\title{
El proceso de privatización Antecedentes, implicaciones y resultados
}

\author{
Eduardo Ramírez Cedillo*
}

\section{Resumen}

El proceso de privatizaciones al que se vio sometido México a partir de los inicios de la década de los ochenta estuvo sustentado bajo un argumento que intentaba justificar su realización y que consistía en destacar la mala administración e ineficiencia de las empresas del Estado. Sin embargo, el proceso de privatización estaba más vinculado con el objetivo de sanear las finanzas públicas, pues se pensaba que la venta de las empresas públicas podría generar flujos de divisas para cubrir el servicio de la deuda y con ello liberar recursos para poder equilibrar dichas finanzas. No obstante que en algún momento del proceso se avanzó en este sentido, los resultados se limitaron a la venta de las paraestatales y posteriormente se regresó a un escenario similar, pero ya sin los activos del Estado; esto es, el cambio de activos por pasivos no arrojó los resultados esperados.

Palabras clave: privatizaciones, eficiencia administrativa, déficit presupuestal, deuda pública.

Fecha de recepción: 22-08-2005

Fecha de aceptación: 11-01-2007

\section{The Process of Privatizations: Background, Implicatios and Results}

\begin{abstract}
The process of privatizations which Mexico from the beginnings of the Eighties was put under was sustained under an argument that tried to justify its accomplishment and that consisted of honoring the bad Administration and the inefficiency of the companies of the State. Nevertheless, the privatization process was more tie with the objective to adjust the public finances. One thought that the sale of the public companies could generate currency flows to cover the payment of the debt and, this way, to release resources to be able to balance the public finances. However, which at some moment of the process it advanced in this way, the results were limited on sale of the State companies and later it was returned to a similar scene, but already without the assets of the State. The change of assets by liabilities did not throw the awaited results.
\end{abstract}

Keywords: Privatizations, Administrative Efficiency, Budget Deficit, National Debt.

\footnotetext{
* Profesor de la Facultad de Contaduría y Administración, UNAM, y de la Universidad Tecnológica de México. Correos electrónicos: ramceed@prodigy.net.mx, ramceed@hotmail.com.

El presente artículo fue posible gracias al apoyo de la beca que, para realizar los estudios de doctorado, fue otorgada al autor por el Consejo Nacional de Ciencia y Tecnología y por la Dirección General de Estudios Profesionales (DGEP-UNAM).
}

No. 222, mayo-agosto 2007:97-114 
Eduardo Ramírez Cedillo

\section{Antecedentes}

A partir de la década de los ochenta se empieza a gestar un cambio en la política Aeconómica en el país derivado de la crisis de los energéticos y de la inestabilidad del sistema monetario internacional de la década anterior. En este contexto, el Estado frenó su crecimiento y disminuyó su intervención en la actividad económica mediante una política de privatizaciones de sus empresas. Esta política de privatización puede ser asumida como la contraparte de la política de nacionalización y creación de empresas públicas que había instrumentado el Estado desde 1917. En 1940, se contaba con 36 empresas públicas que fueron objeto del auge cardenista y, posteriormente, derivado de la política de sustitución de importaciones, el Estado vio incrementar su número de empresas que llegó a ser hasta de 1,155 en el año de $1982 .{ }^{1}$

En 1982, ante un escenario de altos déficits públicos, una elevada y considerable deuda externa y la presencia de niveles importantes de inflación, tanto los acreedores externos como los organismos internacionales fomentaron la política de privatización ${ }^{2}$, encaminada a la disminución del déficit fiscal y la posibilidad del pago de la deuda. ${ }^{3}$

Entre las razones que se han enumerado para llevar a cabo un programa de privatizaciones, están las siguientes: mejorar la eficiencia, mejorar las cuentas públicas, disminuir el poder de los sindicatos, sustituir al sector público por el privado en la toma de decisiones en los mercados de bienes y servicios, crear el capitalismo popular, incrementar la identificación de los empleados con la empresa mediante la tenencia de sus acciones y redistribuir la renta y la riqueza de la sociedad (Valdivieso, 2001: 56). ${ }^{4}$

En este documento se hará referencia tan sólo a dos aspectos: la eficiencia administrativa como objetivo privatizador y la necesidad de privatizar para equilibrar la balanza presupuestal, de capitales y disminuir el pago de la deuda.

\section{La eficiencia administrativa}

Se ha criticado mucho la eficiencia administrativa del sector público para mantener y operar empresas dedicadas a la producción de bienes y servicios que bien pueden ser objeto de

\footnotetext{
${ }^{1}$ Chong y López (2004) presentan un interesante cuadro al respecto del número de empresas públicas desde 1917 a 2003. Ayala (1995: 581), en un estudio al respecto de la intervención estatal, mencionaba que el Estado en los setenta había reclamado para sí la conducción global de la economía mediante mecanismos de coordinación que incidían en aspectos anticíclicos, que sirvieron para apoyar ramas de la economía en dificultades financieras o simplemente para apoyar la rentabilidad de otras.

${ }^{2}$ El 10 de noviembre de 1982 nuestro país firmaba una carta de intención con el FMI, en la cual se comprometía entre otras cosas a superar el desequilibrio externo, abatir los índices de inflación y fortalecer las finanzas públicas. El 19 de enero de 1990 y el 5 de abril de 1991 Pedro Aspe y Miguel Mancera enviaron una carta a Michael Candessus, en la que le mencionaban los logros del gobierno y en la que reportaban, entre otras cosas, los avances en materia de privatización.

${ }^{3}$ Minsburg (1993), al respecto, menciona que "En la mayoría de los países en desarrollo, agobiados por la recesión y la deuda externa, las privatizaciones han sido insistentemente promovidas por los organismos financieros multilaterales, que incluso conceden créditos específicos para profundizar y acelerar ese proceso [...] El objetivo principal de aquellos organismos es abatir el monto de la deuda externa y de su servicio, meta muy ambiciosa si se considera el volumen del débito".
}

${ }^{4}$ En Olías (2001: 56). 
El proceso de privatización: antecedentes, implicaciones y resultados

interés por parte de la iniciativa privada; por lo tanto, la ortodoxia fiscal se postula por la máxima de que el Estado debe transferir a ese sector todas aquellas actividades que puedan resultarle rentables, pero no sólo eso, pues en el caso de participar en otras actividades el Estado deberá asumirse como una institución ejemplarmente eficiente que pueda abatir sus costos de producción y operación (Parguez, 2002). En estos dos postulados encontramos una incompatibilidad debido a que el Estado debe asumir únicamente actividades que no son susceptibles de mercado, es decir, aquellas que dadas sus características no son rentables; consecuentemente, su producción u operación en muchos de los casos tenderá a arrojar aparentemente magros resultados en virtud de que muchas de estas actividades, de carácter social, no arrojan flujos financieros directos ${ }^{5}$ aun cuando pueden arrojar beneficios de manera indirecta a través de los efectos multiplicadores en la economía. ${ }^{6}$

La privatización creciente del sector paraestatal estuvo más vinculada al logro de atraer capitales a la economía, disminuir el déficit presupuestal y el pago de la deuda que a mejorar la eficiencia de las mismas. ${ }^{7}$

Con el proceso de privatización surgieron los detractores del mismo; éstos argumentaban que se incurrían en costos importantes para la sociedad mediante precios más altos, sueldos más bajos y menores ingresos para el gobierno. No obstante, existen algunos estudios que mencionan que estos efectos para el caso de México no se dieron ${ }^{8}$ y cuando ocurrieron se debió más a la regulación inexistente, a las políticas de reestructuración previas y a la falta de contratos debidamente estructurados ${ }^{9}$, elementos que en su momento dieron por resultado fracasos en algunas privatizaciones como fue el caso de las carreteras y el sistema bancario.

Se ha argumentado desde varios ángulos que la privatización de las empresas públicas es deseable en economías de competencia perfecta, pero el problema es que parte de este proceso privatizador ha estimulado la concentración del capital. En gran parte de Latinoamérica, el proceso de privatización consolidó estructuras monopólicas u oligopólicas privadas que en su momento fueron públicas y que veían por el bienestar de la sociedad; ahora solamente ven por el bienestar de su propia rentabilidad sin importar las distorsiones que generen en la consecución de sus objetivos.

Privatizar las empresas estatales, pensando en las fallas del Estado, sería tan sólo caer en el otro extremo constituido por las fallas del mercado. Con un Estado cada vez más reducido incapaz de consolidar estrategias de crecimiento, seguramente las empresas que hoy se

\footnotetext{
${ }^{5}$ Sawyer (1997) opina que el volumen de bienes y servicios ofertados por el Estado, y considerados fuera de mercado (non-market), no le retribuyen un beneficio directo por proporcionarlos debido a que no se venden por dinero en efectivo; en este sentido $-\mathrm{y}$ en ciertos casos - el gasto de gobierno crea bienes intangibles de los cuales no puede ejercer la propiedad y por lo tanto no puede destinar los beneficios generados por sus propias actividades, excepto los que se derivan de niveles más altos de ingresos impositivos como resultado de la aplicación del gasto que propicia el crecimiento económico.

${ }^{6}$ Myrdal (1960: 20-21) menciona que los gastos presupuestarios del Estado asignados a la enseñanza, justicia, defensa, obras públicas, necesidades culturales, socorro contra las crisis, etc., no pueden justificarse por la posibilidad de dar como resultado una ganancia al Estado; estas acciones deberán ser justificadas directamente por las consecuencias sociales y económicas que se espera originen.

${ }^{7}$ Situación que como veremos en el apartado siguiente se logró, pero sólo de manera temporal.

${ }^{8}$ Como se puede consultar en: La Porta y López-de-Silanes (1997), López de Silanes (2002), Sheshinski y López-Calva (1998)

${ }^{9}$ Tal y como se desprende de la lectura de Chong y López de Silanes (2004).
} 
concentran con capital nacional serán en el futuro víctimas de los grandes conglomerados internacionales bajo un escenario de economía abierta.

\section{Consecuencias económicas de la privatización}

Básicamente, el análisis en esta parte estará situado en tres aspectos: el déficit fiscal, la deuda pública y la balanza de capitales.

\section{El déficit fiscal}

Los efectos de la privatización de empresas en el corto plazo será la disminución del déficit fiscal, derivado de la disposición de dinero obtenido en el momento de su venta; en el largo plazo, dependerán de los flujos que se desprendan de esas transacciones. Si las empresas antes de ser privatizadas arrojaban flujos positivos, se esperaría una pérdida en el largo plazo, siempre y cuando estos flujos no sean reemplazados o superados por la captación de impuestos que deberán pagar las nuevas empresas privadas. ${ }^{10}$

De lo anterior esperaríamos, por parte del sector público, un impacto inmediato de la venta, que sería consistente con una reducción del déficit convencional en el periodo de la misma, así como un impacto posterior relacionado a un menor gasto (transferencia) y a una mayor recaudación impositiva.

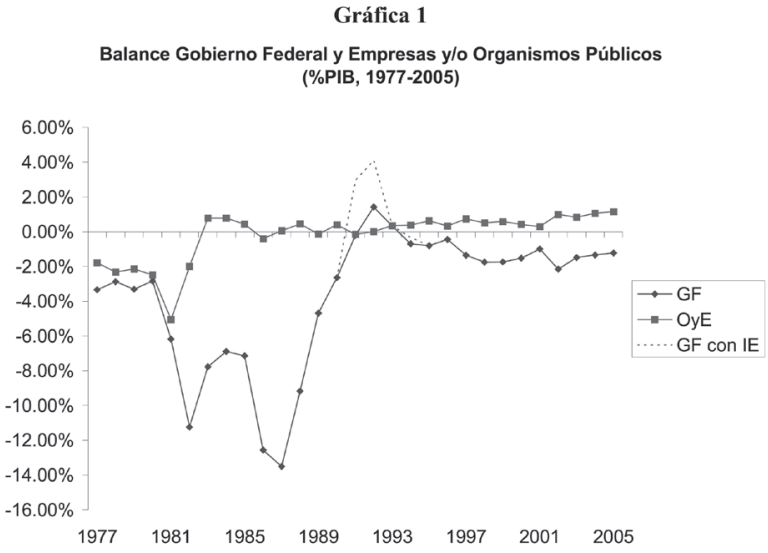

Fuente: Elaboración propia con datos de la Secretaría de Hacienda y Crédito Público

\footnotetext{
${ }^{10}$ Cifuentes (1993) propone que el impacto fiscal de las privatizaciones puede ser formalizado de la siguiente forma:

$$
\begin{aligned}
& I F P=P V-\sum V P+\sum T i \\
& \pi(1+\mathrm{ri}) \pi(1+\mathrm{ri})
\end{aligned}
$$$$
\text { donde: }
$$$$
\mathrm{IPF}=\text { Impacto fiscal de la privatización }
$$$$
\mathrm{PV}=\text { Precio de venta de la empresa }
$$$$
\mathrm{VP}=\text { Flujo de dividendos netos de la empresa de seguir en poder del sector público. }
$$$$
\mathrm{Ti}=\text { Flujos de impuestos pagados por el sector privado }
$$$$
\text { ri }=\text { Tasa de descuento }
$$ 
El proceso de privatización: antecedentes, implicaciones y resultados

Cuando se hace la distinción entre déficit presupuestal correspondiente al gobierno federal (GF) y a los organismos y empresas del Estado (OyE) podemos distinguir cómo a raíz de que comienza el proceso de privatizaciones se estabiliza el déficit correspondiente a organismos y empresas públicas; no obstante, el déficit del GF sigue presente y sólo es superado con los ingresos extraordinarios (IE) de 1991, 1992 y 1994 (como lo indica la línea punteada en la gráfica 1), con lo que podemos argumentar, al igual que en varios estudios, que las ventas de las empresas del Estado solamente tienen efectos positivos para el déficit en el momento que se recibe el pago por su compra. ${ }^{11}$

Desde luego, mucho se ha argumentado que si hay déficit presupuestal en México se debe al pago de los intereses que por concepto de deuda tienen que ser cubiertos. Si descontamos ese pago de intereses, podemos apreciar claramente que hemos sido superavitarios, desde por lo menos el año de 1983, como se aprecia en la gráfica 2.

Gráfica 2

Balance Primario, Gobierno Federal y Organismos y Empresas Públicas (\% PIB, 1977-2005)

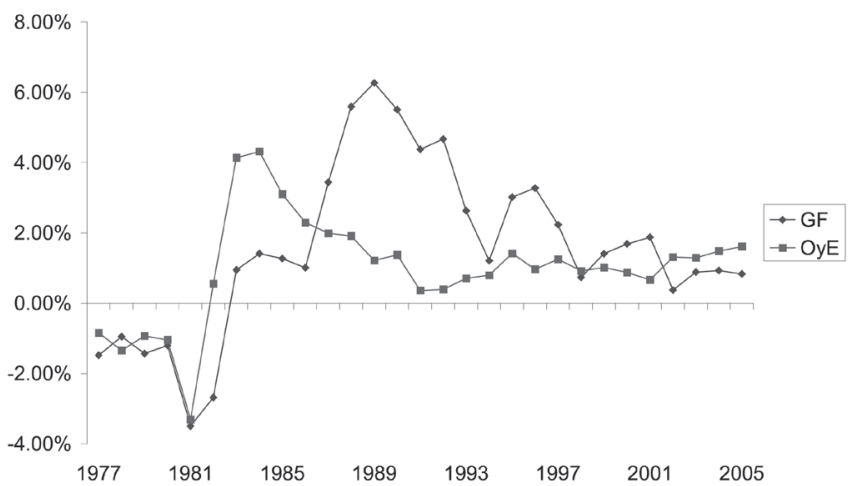

Fuente: Elaboración propia con datos de la Secretaría de Hacienda y Crédito Público

Resulta interesante comentar que incluso el superávit primario se ha venido disminuyendo y ha resultado ampliamente inestable, lo que se puede asumir como una prueba de la poca sustentabilidad para seguir manteniendo la misma tendencia de política económica. La disminución del déficit y el mantenimiento de los superávit, que se aprecian en los organismos y empresas del sector público en las gráficas 1 y 2 , se deben principalmente a la privatización, a la fusión y al cierre de un gran número de empresas con lo cual se disminuyó en buena parte las partidas dedicadas a este propósito.

\footnotetext{
${ }^{11}$ Ruiz (2002) menciona que la experiencia peruana y la de varios países de la región han demostrado que las privatizaciones no generan un sistema de financiamiento público sustentable en el tiempo y que tan sólo se han constituido como un paliativo de corto plazo que concluye tan pronto finaliza la venta. Por su parte, Azpiazu y Schorr (2001) concuerdan con los beneficios de corto plazo de las privatizaciones en Argentina; sin embargo mencionan que, agotado el primer impacto derivado de los ingresos efectivos y de la supresión de los servicios de la deuda capitalizada, las cuentas públicas se vieron nuevamente erosionadas.
} 
El balance operativo, resultado de la sustracción de los ingresos de las empresas por la venta de bienes o servicios y los gastos operativos en que éstas incurren, se vio efectivamente mejorado (gráfica 3); no obstante, después de 1995 la tendencia se revirtió y se comenzó nuevamente con una escalada descendente. La razón de este balance deficitario la podemos encontrar en el incremento del pago de pensiones por arriba de las cuotas que perciben nuestras instituciones de seguridad social, el IMSS y el ISSSTE, situación que se ha consolidado como un problema importante para las finanzas públicas. En la gráfica 4, podemos apreciar cómo se ha modificado la estructura del gasto y cómo ha ganado terreno el rubro de servicios generales, en el que se considera el pago de pensiones.

\section{Gráfica 3}

Balance Operativo, Corriente y Financiero, sin PEMEX (\%PIB, 19772005)

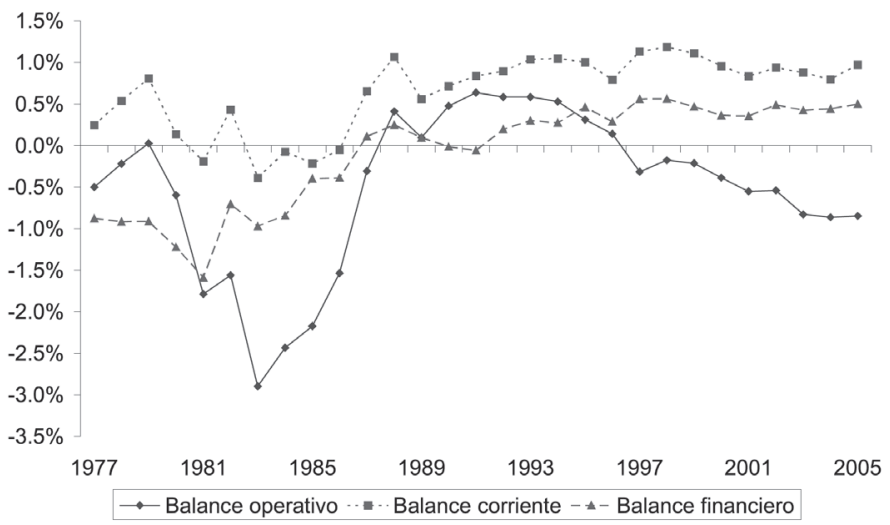

Fuente: Elaboración propia con datos de la Secretaría de Hacienda y Crédito Público

Las variaciones positivas del balance corriente se explican de manera sencilla por las transferencias que realiza el gobierno federal a dichos organismos de seguridad social y que, cabe mencionar, van en aumento (para 2003, las transferencias del gobierno federal al IMSS eran aproximadamente de $1 \%$ del PIB y en el caso del ISSSTE del $0.30 \%$ ).

Por último, en lo que respecta al saldo positivo en el balance financiero, podemos argumentar que es resultado de la reducción en la inversión física, como lo podemos ver en el gráfico 5. Alcanzamos balances financieros positivos a costa del deterioro de la infraestructura pública, a costa del deterioro de los servicios de seguridad social, a costa de quedar rezagados en el uso de tecnología, etc. A la larga, este ahorro resultará más oneroso, pero además cómo se pretende que la empresa pública sea eficiente si no cuenta con los medios necesarios para realizar sus funciones; en la gráfica 4, podemos observar que el gasto en suministros y materiales ha sufrido disminuciones que seguramente irán en detrimento de las siete entidades que aún forman parte del control presupuestal del Estado. 
El proceso de privatización: antecedentes, implicaciones y resultados

Gráfica 4

Composición del gasto de operación (1977-2005)

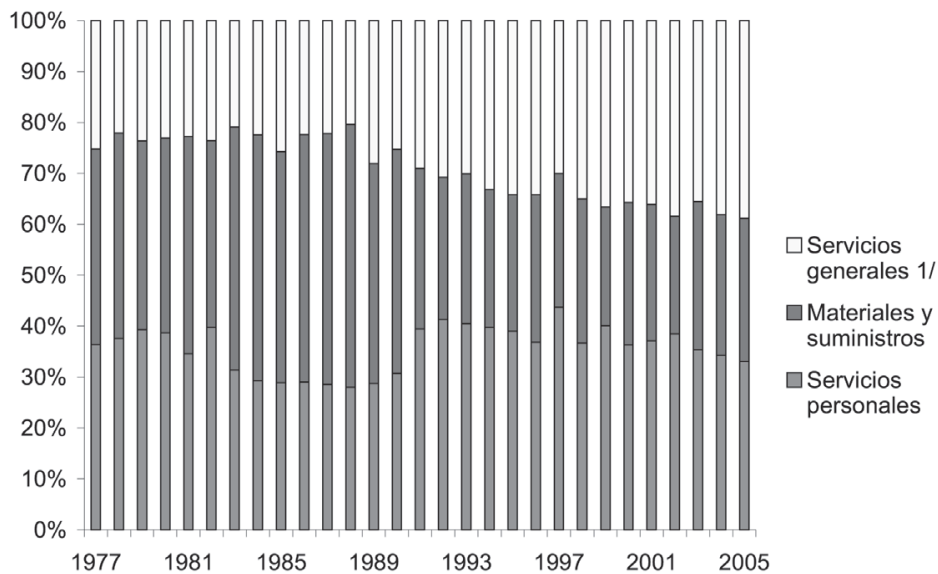

Fuente: Elaboración propia con datos de la Secretaría de Hacienda y Crédito Público 1/ el rubro de servicios generales va adicionado con las pensiones.

De lo anterior, podemos concluir que los beneficios de la disminución de aparato gubernamental no resultaron en beneficios permanentes y por eso surge la necesidad de replantear las nuevas propuestas de privatización. La privatización resultará pertinente siempre y cuando se realice como una estrategia de política económica; es diferente que el Estado en una fase de expansión decida participar a los particulares de la actividad económica a que lo haga cuando se encuentra en una fase de recesión.

\section{Gráfica 5}

Inversión Física (\%PIB, 1977-2005)

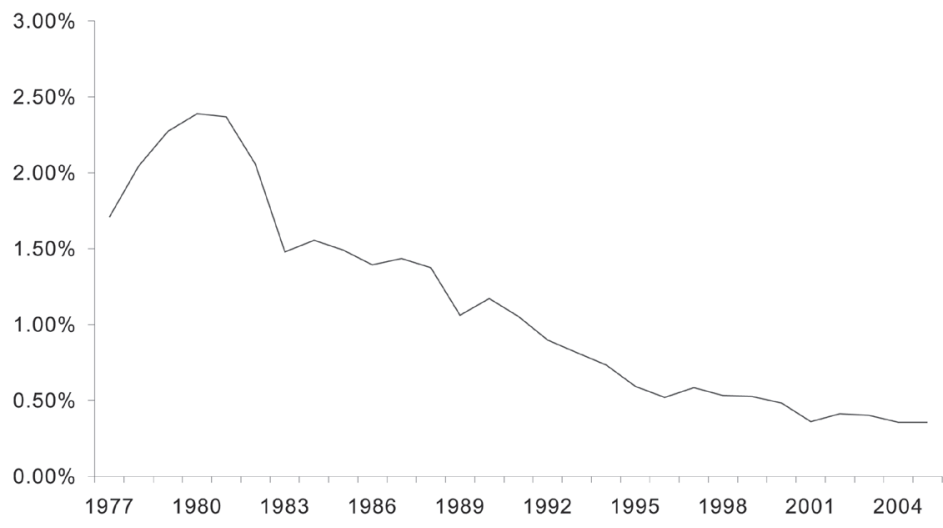

Fuente: Elaboración propia con datos de la Secretaría de Hacienda y Crédito Público 
Otro punto de interés que maneja la ortodoxia fiscal consiste en considerar que el proceso de privatización puede tener beneficios en el futuro a medida que las nuevas empresas desnacionalizadas empiezan a cubrir sus obligaciones fiscales; pero en nuestra economía la evidencia no es suficiente ni concluyente en este sentido.

Gráfica 6

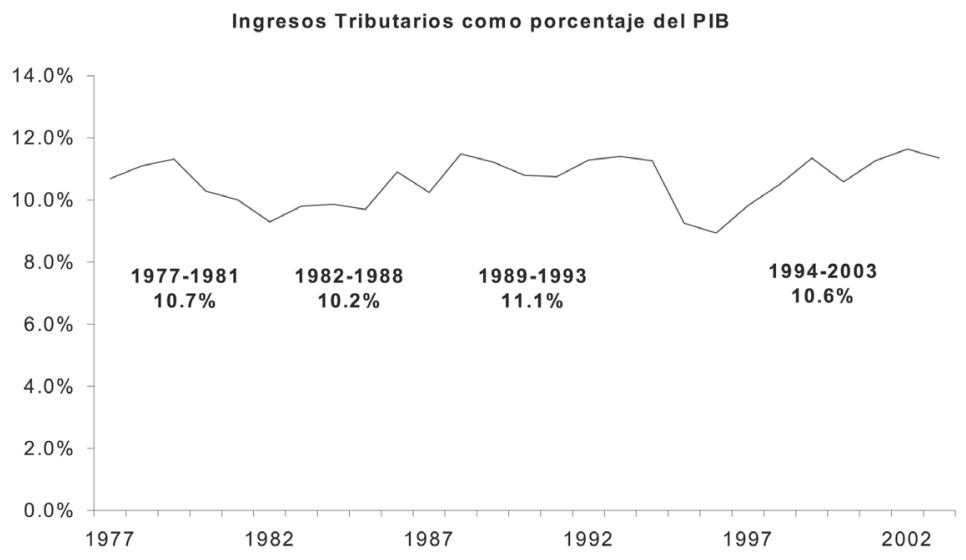

Fuente: Elaboración propia con datos de la Secretaría de Hacienda y Crédito Público

Como se aprecia en la gráfica 6, el promedio de los ingresos tributarios de 1977 a 2003 ha sido de $10.6 \%$ del PIB y si bien se podría argumentar que en el periodo de 1989-1993, en el cual se dio el auge privatizador, los ingresos tributarios se incrementaron por arriba del promedio con una cantidad de $11.1 \%$, esto se podría tomar como una validación de que la privatización tiene efectos positivos de largo plazo. Se mantiene que el determinante de la recaudación tributaria es el crecimiento económico, lo que es consistente con la visión procíclica de los impuestos. Adicionalmente, en 1979 no se había privatizado nada y la recaudación era similar a la obtenida en años posteriores.

\section{La deuda pública}

Para los países latinoamericanos, la política de privatizaciones representó un proceso de cambio de activos por pasivos, que en apariencia resultó exitoso en la medida que se disminuyó la carga de la deuda que pesaba sobre ellos y se liberaban recursos dedicados al pago de los intereses; por lo tanto, se tenía un manejo menos restricto de los recursos del Estado. No obstante, la propia ortodoxia, encabezada por el consenso de Washington, exigía seguir trabajando con disciplina fiscal.

Si bien con la privatización de las empresas públicas se avanzó en el pago de la deuda externa, este proceso al no derivarse en una transformación estructural de largo plazo se revirtió, por lo que en estos momentos nuestra economía sufre de nueva cuenta los 
El proceso de privatización: antecedentes, implicaciones y resultados

embates de otro endeudamiento ${ }^{12}$, caracterizado por una deuda interna creciente que nos ubica en situaciones similares a las vividas en los inicios de los noventa, pero bajo un escenario diferente donde el Estado tiene menos riqueza y un menor margen de maniobra para poder repudiar su deuda mediante una mayor inflación o con el manejo de su política cambiaria.

En términos generales, podríamos mencionar que la deuda externa se ha venido reduciendo. En 1982 constituía el 32.5\% del PIB; en los años de 1986-1987 alcanza su mayor proporción del PIB ubicándose en niveles del 60\% del producto; de 1988 y hasta la crisis de 1994-1995, se instrumentan acciones importantes en la disminución y renegociación de la deuda, las cuales permitieron disminuir dicha deuda al pasar del máximo observado en 1987 a tan sólo $19.5 \%$ del PIB en $1993^{13}$ (esto se muestra en la gráfica 7).

Para algunos analistas, la forma en que se logró la negociación de la deuda estuvo supeditada al compromiso de instrumentar algunas medidas de política económica, tales como la desregulación de los mercados, la liberalización financiera, la privatización de las empresas públicas, las finanzas públicas sanas, el proyecto de ley para otorgarle autonomía al Banco de México y la posible aprobación del Tratado de Libre Comercio. Algunas de las medidas anteriores tenían como objetivo estabilizar la economía, aun a costa del crecimiento. ${ }^{14}$ Chossudovsky (1988), a diferencia de lo que comentaba Salinas de Gortari, mencionaba que la única alternativa viable para los países del tercer mundo con problemas de deuda es la condonación de la misma; asimismo, argumentó que las negociaciones de la deuda implicaban reestructuraciones económicas que se constituían en verdaderas camisas de fuerza que impedían buenos resultados.

De acuerdo con Chossudovsky, los países endeudados aceptaban las políticas impuestas por el FMI no sólo por ser un requisito para obtener financiamiento de ese organismo internacional, sino también por que la aceptación se consideraba como un aval para que las instituciones bancarias privadas y estatales acreedoras otorgaran paquetes de renegociación a las naciones endeudadas. El problema es que estas políticas de ajuste conllevaban a menor solvencia crediticia y a mayor inestabilidad financiera; en pocas palabras, la solución de la crisis se volvía la causa del exceso de la deuda. No pasó mucho tiempo para que fuera evidente que el camino iniciado en 1988 tendría resultados poco satisfactorios.

\footnotetext{
${ }^{12}$ Azpiazu y Schorr (2001) mencionan que incluso para Argentina la disminución de la deuda del intercambio de activos por pasivos fue compensada por el nuevo endeudamiento que se derivó del propio proceso de privatizaciones al asumirse los pasivos de las empresas por privatizar.

${ }^{13}$ En junio de 1989, el entonces presidente de la nación, Carlos Salinas de Gortari, anunciaba la solución a los problemas de la deuda externa que aquejaban al país en aquel entonces y mencionaba que, si bien ninguna negociación internacional en marcha había propuesto eliminar por completo el endeudamiento, en México habíamos resuelto ya el problema de la carga excesiva de la deuda que pesaba sobre los hombros de los mexicanos (mensaje a la nación, 23 de junio de 1989).

${ }^{14} \mathrm{Al}$ igual que el plan Baker, el plan Brady imponía ciertas condiciones a los países deudores. Principalmente, señalaba la necesidad de aplicar reformas que impulsen la inversión y el ahorro internos, así como crear un entorno de confianza para los capitales foráneos. Se insistía en que deben mantenerse y agilizarse los procesos de privatización y de reducción del gasto público (Castro, 1993).
} 
En 1994, la disminución de la deuda rompe su tendencia descendente y vuelve una vez más a incrementarse, lo anterior en virtud de eventos que para algunos fueron inesperados, como lo comentan Patrap, Lobato y Somuano (2003):

El colapso fue inesperado. La caída de las reservas internacionales resultado del malestar político al inicio de 1994 junto con un ataque especulativo contra el peso forzó a una devaluación nominal del 44 por ciento en diciembre de 1994, eso restringió el acceso de la economía al ahorro externo. Bajo esta circunstancia cualquier déficit de cuenta corriente para 1995 fue imposible de ser financiado. El colapso en la producción y el gasto fueron inevitables y las medidas de ajuste interno sucedieron. El producto cayó 6.2 por ciento en 1995, la inversión de capital disminuyó 29 por ciento en 1995, la inflación subió de nuevo a una tasa anual de 52 por ciento y la tasa de interés nominal alcanzó un máximo de 71.5 por ciento en abril de 1995.

Sin embargo, para otros la crisis vivida en 1994, si bien puede asumirse como un problema con ciertos matices de carácter político que causaron la inestabilidad del sistema y los resultados conocidos, no fue el elemento detonante de los desequilibrios:

Las consecuentes reducciones de las reservas internacionales no fue resultado de los problemas sociales y políticos manifestados en ese año [...] Los problemas del déficit creciente de cuenta corriente, la menor entrada de capitales, el mayor endeudamiento externo de corto plazo, así como las menores condiciones de rentabilidad y crecimiento que ofrecía la economía nacional fueron las verdaderas causas de la incertidumbre cambiaria (Huerta, 1996: 81).

Lo cierto es que de 1995 (año en el cual se incrementa nuevamente a un punto máximo la deuda externa, 35\% del PIB) a la fecha el comportamiento de la deuda externa ha sido un proceso continuo de disminución, teniendo un saldo promedio trimestral en 2003 de alrededor de $12.8 \%$ del PIB.

Gráfica 7

Deuda bruta (\%PIB, 1982-2003)

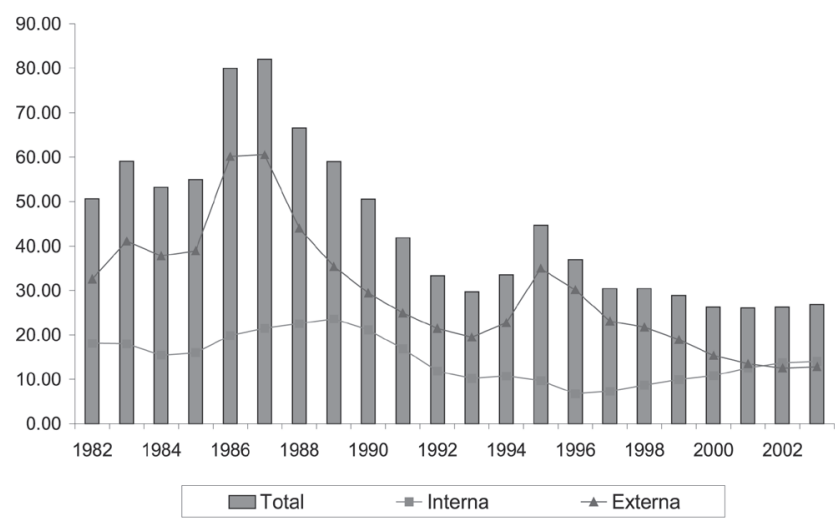

Fuente: Elaboración propia con datos de la Secretaría de Hacienda y Crédito Público 
El proceso de privatización: antecedentes, implicaciones y resultados

Es necesario comentar que si bien es cierto que se ha dado una disminución de la deuda externa, la deuda interna se ha venido incrementando de manera constante desde 1996, año en el cual tuvo su nivel más bajo (cerca del $6.8 \%$ del producto, como se puede apreciar en la gráfica 7), esto sin considerar la deuda denominada contingente, correspondiente a los fondos del IPAB (antes FOBAPROA) el rescate carretero y fideicomisos como el FIDELIQ, el FIRA, FOVI, el FAMEVAL, etc. (ver gráficas 8 y 9). Desde luego que la deuda contingente presentada hasta este momento no cuantifica el problema relacionado con la seguridad social que se constituye como un importante problema de deuda contingente por parte del gobierno federal; asimismo, queda fuera de la presentación gráfica, por ahora, la deuda de los estados y los municipios. ${ }^{15}$

Del gráfico 8 podemos apreciar cómo la disminución de la deuda contingente se asocia a un incremento de la deuda interna, esto en virtud de que año con año el gobierno federal asume una parte de la deuda contingente de manera práctica y formal. Por otra parte, apreciamos que, aun cuando se ha disminuido la deuda externa, el incremento de la deuda interna es notable, por lo que podemos deducir que en cierta medida tan sólo se ha realizado un cambio de deuda externa por deuda interna ${ }^{16}$; Vidal (2004) menciona que, en el caso de los Tesobonos, de deuda interna pasó a ser deuda externa con la clara necesidad de dólares o alguna otra divisa para su servicio y administración. Siguiendo con lo mismo, Correa (2004) argumenta que aunque los bonos del IPAB se denominan en pesos y sus intereses se fijan en pesos, la gran mayoría de sus tenedores no son residentes ${ }^{17}$; por lo tanto, estos bonos actúan en nuestro contexto económico como deuda externa. Pero no sólo los Tesobonos y los bonos del IPAB pueden considerarse como deuda externa en la medida que más agentes económicos externos inviertan en papel de deuda gubernamental; así, las presiones exteriores se irán intensificando en la dimensión que los tenedores hagan efectivos los documentos.

\footnotetext{
${ }^{15}$ Arturo Guillén (2004) presenta la cuantificación total de la deuda interna en cuatro rubros generales: i) deuda consolidada (documentos gubernamentales), ii) deuda contingente (programas de recate), iii) deuda de las entidades federativas y los municipios, y iv) fondos de pensiones. Considerando esta agregación de la deuda, Guillén nos presenta una estimación de deuda interna alrededor de 40.1 y $40.5 \%$ del PIB para 2001 y 2002 respectivamente.

${ }^{16}$ En este sentido Hernández (2003: 143) menciona que, dada la crisis de deuda externa vivida en 1982, se suscitó una fuerte inestabilidad financiera reflejada en altas tasas de inflación y ajustes del tipo de cambio; ante estos eventos y la contracción de los créditos externos, el país tuvo que desarrollar y profundizar un mercado interno de valores gubernamentales que permitiera hacer frente a los requerimientos financieros inmediatos con un aparente menor costo y consolidar la política de deuda pública como una política macroeconómica.

${ }^{17}$ La doctora Correa, al mencionar a los no residentes, se refiere a los nuevos banqueros que son en cierto sentido los beneficiarios de los documentos.
} 
Gráfica 8

Deuda bruta (\%PIB, 1982-2003)

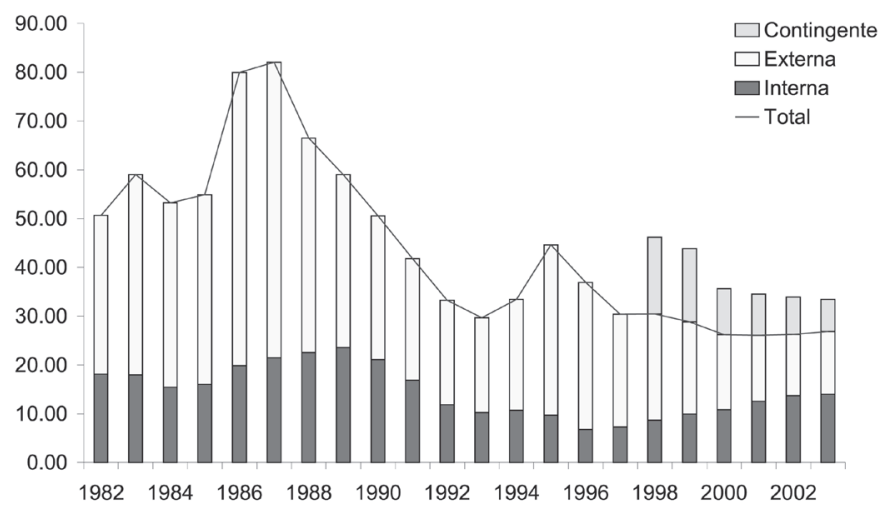

Fuente: Elaboración propia con datos de la Secretaría de Hacienda y Crédito Público

Un aspecto medular del intercambio de deuda externa por interna radica en el costo de una y otra, situación que es preocupante cuando la política económica del gobierno consiste en el manejo de altas tasas de interés que inciden directamente sobre el costo de la deuda interna. En el corto plazo, y salvo que se diera la reforma eléctrica, no se aprecia que esta política de altas tasas de interés tenga un viraje hacia la baja; por lo tanto, estaremos en condiciones de un mayor servicio de deuda. Cuando un país como México, no ofrece condiciones productivas que puedan ser rentables a la inversión extranjera, es necesario brindar una tasa de interés más atractiva que considere el riesgo país, a menores condiciones de rentabilidad en el Sector Productivo.

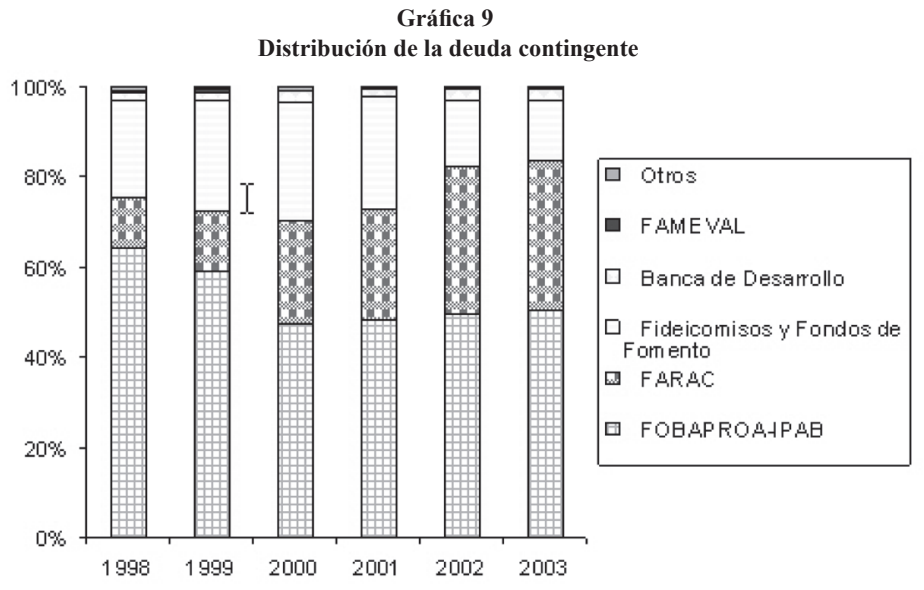

Fuente: Elaboración propia con datos de la Secretaría de Hacienda y Crédito Público 
El proceso de privatización: antecedentes, implicaciones y resultados

En cuestión de deuda, tanto interna como externa, así como la contingente ${ }^{18}$, es claro que seguimos en niveles de endeudamiento similares a los observados en la década de los noventa. En 2003, se cuantifica una deuda total de $33.45 \%$ del PIB, cantidad similar a la observada en 1994; a diez años de distancia seguimos teniendo la misma cantidad de deuda total, con la única diferencia que la deuda externa se ha disminuido de 22.7 a $12.8 \%$ con respecto del PIB.

Si bien es cierto que el nivel de deuda del $33.45 \%$ del PIB constituye una fuerte presión para las finanzas públicas, esta cantidad tan sólo es aproximadamente la mitad de la deuda total, a la que en un momento dado se puede llegar a enfrentar el país. Guillén (2004), en una estimación conservadora para el año 2002, considera que la deuda total es de aproximadamente el $66.4 \%$ :

[...] la deuda total de México al cierre de 2002 (externa e interna) es equivalente a 423,397 MD, de la cual 165, 115 MD (39\% del total) es externa y 258,282 MD (61\%) es interna. Vista la deuda total como proporción del PIB -y esto es lo más importante como medida del grado de endeudamiento-, representa el $66.4 \%$ del PIB al terminar 2002. La deuda externa total significa el $25.9 \%$ del PIB, mientras que la deuda interna alcanza el $40.5 \%$, destacando dentro de esta última los programas de rescate financiero y los pasivos laborales de los institutos de seguridad social que absorben el 19.2\% y el 5.8\% de la producción nacional, respectivamente.

La deuda externa a la que se refiere Guillén se ve incrementada con la deuda de los agentes privados y los Pidiriegas que representan el $10.4 \%$ y el $2.4 \%$ del PIB, respectivamente.

\section{La balanza de capitales}

En principio, se sostiene que el efecto del proceso de privatizaciones en la balanza de capitales será positivo en virtud de los flujos provenientes del extranjero para la compra de los activos estatales; posteriormente, se esperarían ingresos adicionales por las inversiones en tecnología y mejoras que realizaran los nuevos propietarios, además de que se pueden anticipar flujos de salida por remisión de utilidades, dividendos al exterior y pago de intereses.

Una de las finalidades de la apertura económica consistía en atraer ahorro externo al país para poder financiar proyectos de inversión en la economía, contar con los recursos para cumplir con el servicio de la deuda y estar en condiciones de financiar el déficit de cuenta corriente.

A medida que se fue dando la apertura económica, la inversión extranjera se incrementó, aun cuando el aumento temprano de la inversión estuvo asociado más a inversiones de cartera que a inversiones directas; lo anterior es un escenario que presenta signos de fragilidad en la economía en virtud de la inestabilidad de la inversión de cartera.

A su vez, la inversión directa ha ido disminuyendo su capacidad para incentivar negocios nuevos e innovadores; de igual manera, la composición de la inversión extranjera directa se ha venido modificando y ésta cada vez se consolida más como un intercambio de cuentas entre las empresas transnacionales filiales en el país y su casa matriz (como se puede apreciar en la tabla 4).

\footnotetext{
${ }^{18}$ Sin considerar hasta el momento la seguridad social y la deuda de estados y municipios.
} 
Tabla 4

Inversión extranjera directa

\begin{tabular}{lrrrc}
\hline & $\begin{array}{c}\text { Nuevas } \\
\text { inversiones }\end{array}$ & Reinversiones & \multicolumn{1}{c}{$\begin{array}{c}\text { Cuentas con } \\
\text { la matriz }\end{array}$} & \multicolumn{1}{c}{ Total } \\
\hline \hline $1982-1988$ & $78.70 \%$ & $26.20 \%$ & $-4.90 \%$ & $100.00 \%$ \\
$1989-1994$ & $58.60 \%$ & $32.40 \%$ & $9.00 \%$ & $100.00 \%$ \\
$1995-2000$ & $56.50 \%$ & $21.30 \%$ & $22.10 \%$ & $100.00 \%$ \\
$2001-2003$ & $43.70 \%$ & $20.10 \%$ & $36.10 \%$ & $100.00 \%$ \\
\hline
\end{tabular}

Fuente: Elaboración propia con datos del Banco de México

En el periodo de 1982 a 1988, el rubro correspondiente a nuevas inversiones, es decir, aquellos flujos de recursos que ingresan al país para aportar al capital de una empresa, ya sea para establecerla por primera vez o para aumentar el capital de una ya existente, alcanzaban el $78.7 \%$ del total de la inversión en cartera, pero ya para el periodo de 2000-2003 tan sólo representaba el $43.7 \%$. El rubro de reinversiones, o sea, aquella parte de las utilidades que una empresa de inversión extranjera genera en el país y que en vez de repartirse a los inversionistas extranjeros se reinvierten en la propia empresa, también se disminuyó de $26.2 \%$ a $20.1 \%$, respectivamente, en los periodos anteriormente mencionados. El rubro de inversión extranjera directa que se incrementó fue el de cuentas con la matriz, que podemos resumir como las relaciones que guarda la filial en el país con su matriz en el exterior, por ejemplo, si la filial se endeuda con su matriz, ese préstamo se considera un ingreso en cuentas con la matriz y por lo tanto forma parte de la inversión extranjera directa.

La modificación en la composición de la inversión extranjera directa resultará poco satisfactoria porque la inversión directa que se necesita en el país tiene que ver con aquella inversión que genera nuevas empresas o hace crecer a las ya existentes, por lo que de poco sirven los cambios patrimoniales. En el caso de empresas que ya están funcionando, como son los bancos o las tiendas de autoservicio, y son objeto de la inversión extranjera para su compra no están generando nuevas fuentes de empleo, pues en el mejor de los casos mantiene los ya existentes.

\section{Gráfica 10}

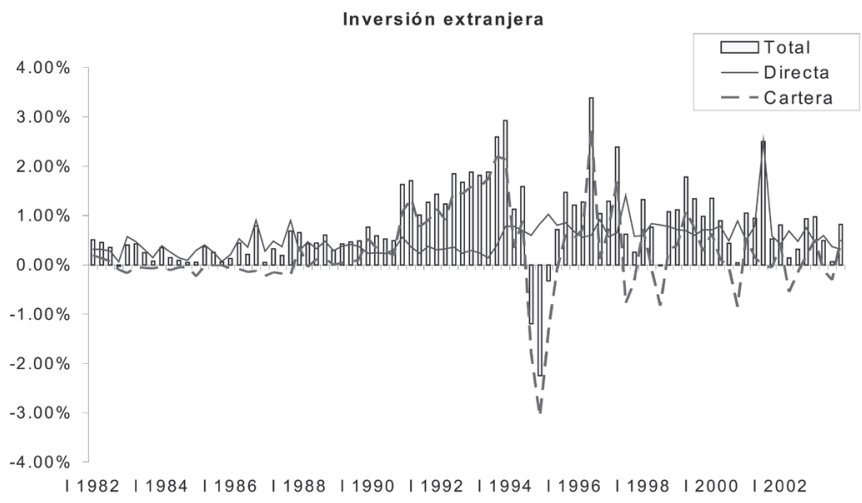

Fuente: Elaboración propia con datos del Banxico 
El proceso de privatización: antecedentes, implicaciones y resultados

Por su parte, la inversión de cartera hasta 1988 correspondía tan sólo a valores emitidos en el extranjero; cabe señalar que para 1986 tan sólo por parte del gobierno y a partir de 1987 también por el sector privado no bancario. En 1989, se empieza a reportar una participación importante de flujos de inversión hacia el mercado accionario; pero va a ser hasta 1991 cuando la captación de inversión extranjera de cartera se ponga a funcionar a su máxima capacidad, bajo tres mecanismos principalmente: mercado accionario, valores en moneda nacional y valores emitidos en el extranjero (como se puede apreciar en la gráfica 10).

El problema principal de los flujos extranjeros de inversión a la economía radica esencialmente en los mecanismos que se utilizan para atraerlos. por una parte la inversión de cartera reacciona a una relación riesgo-rendimiento, en la cual dentro de ciertos rangos la inversión de cartera responderá satisfactoriamente a las primas de riesgo que ofrezca el país, siempre y cuando existan las garantías suficientes que amparen el incremento en la tasa de riesgo. Por su parte, la inversión directa responderá a las expectativas de rentabilidad que generan los sectores estratégicos gubernamentales que sigan en la lista de este proceso de privatización. ${ }^{19}$ No obstante, éste es un proceso finito, pues una vez que se carezca de activos estatales rentables no existirá mayor atractivo del capital extranjero por nuestra economía.

\section{Conclusión}

En conclusión, se tiene que el proceso de privatización de las empresas públicas no ha tenido los resultados que se buscaban como se describe con algunos hechos estilizados que devienen del desarrollo del trabajo.

La privatización de las empresas públicas no mejora la administración de esas unidades económicas, ni tampoco se puede dar por sentado que con la privatización se va a generar un ambiente de mayor competencia; al contrario, la concentración del capital privado transformó los monopolios estatales en monopolios privados (Telmex) o bien en empresas extranjeras (sistema bancario), con el inconveniente de que los involucrados o nuevos propietarios tienen injerencia en las decisiones de política económica que adopta el Estado y en cualquier caso tratarán de favorecerse a costa de la población en general.

Por otra parte, la privatización no condujo a mejoras en el comportamiento de las finanzas públicas, pues los efectos que se tuvieron fueron tan sólo de corto plazo, pero con el agravante de que se regresaba a una situación similar en condiciones de desventaja con menor cantidad de activos y con una cantidad de pasivos similar o mayor a la de la década de los ochenta (si consideramos la pesada losa que representa la bancarrota de la seguridad social); a la luz de los hechos, parece poco rescatable haber optado por intercambiar activos por pasivos.

Un aspecto que queda velado en el desarrollo del trabajo es el trasfondo de intereses que conlleva el proceso de privatización. Por una parte, dicho proceso ha permitido que se amplíe la esfera de participación de la iniciativa privada en sectores que anteriormente habían sido exclusivos del Estado; por otra ha, jugado un papel fundamental en la estabilización monetaria.

\footnotetext{
${ }^{19}$ Comisión Federal de Electricidad (CFE) y Petróleos Mexicanos (Pemex).
} 
Para mantener el valor de la moneda con respecto al dólar, se requiere ofrecer activos rentables al capital extranjero. En una economía como la mexicana que no garantiza la rentabilidad en el nivel general en los sectores productivos por su bajo desempeño, los capitales externos tan sólo estarán dispuestos a participar en el mercado doméstico en aquellos sectores productivos con amplia rentabilidad asegurada, como en la actualidad es el caso de Pemex y la $\mathrm{CFE}^{20}$, o bien participarán en el mercado financiero siempre y cuando las condiciones de riesgo y rendimiento sean atractivas.

Para ofrecer condiciones atractivas en el sector financiero, el gobierno crea certidumbre manteniendo una política fiscal en equilibrio, es decir, se restringe a una política de gasto determinada por su nivel de ingresos en lo que se ha dado a llamar finanzas públicas sanas. El equilibrio fiscal tiene implicaciones sobre el proceso de privatización al menos en dos sentidos: dada la escasez de los recursos por parte del gobierno se ve imposibilitado de emprender proyectos de inversión, por lo que tiene que recurrir al sector privado interno y externo; asimismo, ante el menor crecimiento económico se ve en la imposibilidad de mantener la sanidad de las finanzas públicas, situación que lo orilla a la venta de activos.

Si se acepta que la entrada de capitales es un requisito para la estabilidad monetaria, las preguntas serían: ¿el proceso de privatización es crucial para la entrada de capitales? ¿será la única manera de atraerlos? La respuesta, tomando como referencia la estabilidad monetaria, es positiva en virtud de que dicha estabilidad obliga el uso de la disciplina fiscal; pero una economía con tipo de cambio flexible que utiliza su política fiscal para incentivar el crecimiento y es acompañada de la política monetaria en tal objetivo ${ }^{21}$ puede lograr la entrada de capitales ante las oportunidades de rentabilidad que genera su fase ascendente, sin que ello dependa de la privatización de los sectores paraestatales altamente rentables y estratégicos.

La atracción de los capitales hacia México en sectores productivos se puede lograr mediante el crecimiento económico, haciendo más atractiva la esfera productiva que la financiera. Para ello se requiere la flexibilización del tipo de cambio que permita de nueva cuenta el manejo soberano de la política económica, en la que se pueda instrumentar una política fiscal contra-cíclica que sea acompañada de la política monetaria, sin dejar de lado la revisión a la apertura económica. Lamentablemente, la apuesta es por la liberalización comercial, la estabilidad monetaria y la disciplina fiscal que conlleva a la privatización de las empresas del Estado, proceso que no arrojó los resultados que de él se esperaban. ${ }^{22}$

\footnotetext{
${ }^{20} \mathrm{~A}$ tal respecto, se puede revisar la exigencia de la apertura del sector energético por parte de los empresarios nacionales expuesta por Huerta (2003).

${ }^{21}$ Wray (2004) argumenta que es común la creencia de que el gobierno encara una restricción presupuestal y que por lo tanto el gasto debería ser financiado por impuestos, préstamos o creación de dinero. Sin embargo, dado que muchas economías, en la actualidad, prohíben la creación directa de dinero, se asume que el financiamiento sólo puede ser posible con la complicidad del banco central.

${ }^{22}$ Por motivos de espacio, tan sólo se deja como una inquietud el trasfondo de intereses que tiene el proceso de privatización; no obstante, para abundar sobre algunas afirmaciones que se hicieron al final de las conclusiones tales como la necesidad de una política cambiaria flexible, la relación de la política fiscal y el crecimiento económico, el planteamiento de finanzas públicas sanas y las implicaciones de una política fiscal contracíclica, se puede revisar Ramírez (2006a, 2006b y 2006c).
} 
El proceso de privatización: antecedentes, implicaciones y resultados

\section{Bibliografía}

AYALA J., "Límites y contradicciones del intervencionismo estatal", en Desarrollo y Crisis de la Economía Mexicana, México, Fondo de Cultura Económica, 1981, pp. 574-588 (Lecturas del Trimestre Económico No. 39).

AZPIAZU, D. y M. SCHORR, Privatizaciones, rentas de privilegio, subordinación estatal $y$ acumulación del capital en la Argentina contemporánea, Instituto de Estudios y Formación de la Central de Trabajadores Argentinos (CTA), Argentina, 2001.

CASTRO, A., "Deuda externa: avances y sinsabores del esfuerzo regional", en Comercio Exterior, vol. 43, no. 1, enero 1993, pp. 58-78.

CHONG, A. y F. LÓPEZ DE SILANES, "Privatization in Mexico", en Banco Interamericano de Desarrollo (BID), Working Paper \#513, agosto 2004.

CHOSSUDOVSKY, M., "Una propuesta para cancelar la deuda del tercer mundo", en Comercio Exterior, vol. 38, no. 11, noviembre 1988, pp. 1017-1020.

CORREA, E., "Deuda externa y mercados financieros", en http://www.redcelsofurtado. edu.mx, 2004, consultado el 30 de marzo de 2005.

GUILLÉN, A.,"México: deuda y desarrollo económico", Ponencia presentada en el Seminario Internacional Amerique Latine et Caraibe: Sortir de l'impasse de la dette et de l'ajustement, organizado por el Comité para la Anulación de la Deuda del Tercer Mundo (CADTM) con la colaboración del Centro Nacional de la Cooperación y el Desarrollo (CNCD), Bruselas, Bélgica, 23-25 de mayo de 2003.

HERNÁNDEZ, F., La economía de la deuda, lecciones para México, México, Fondo de Cultura Económica, 2003.

HUERTA, A., Causas y remedios de la crisis económica de México, México, Diana, 1996.

, "Gobierno, gasto público y empresarios”, en Economía Informa, núm. 318, Facultad de Economía, Universidad Nacional Autónoma de México, julio-agosto 2003, pp. 14-22.

LA PORTA, F. y F. LÓPEZ DE SILANES, "The Benefits of Privatization: Evidence from Mexico", Nacional Bureau of Economic Research, Working Paper No 6215, octubre 1997.

MÉXICO Y EL FMI: LA CARTA DE INTENCIÓN, en Comercio Exterior, vol. 32, no. 11, noviembre 1982, pp. 1247-1259.

MINSBURG, N., "Política privatizadora en América Latina", en Comercio Exterior, vol. 43, no. 11, noviembre 1993, pp. 1060-1067.

MYRDAL, G., "Los Efectos Económicos de la Política Fiscal”, Madrid, M. Aguilar Editor, 1960. 
OLÍAS, B., La nueva gestión pública, España, Pretince Hall, 2001.

PARGUEZ, A., "The Paradox of Fiscal Discipline Policy Into Contemporary Capitalist Economies An Inquiry Into The Poverty of Nations", escrito para The Seventh International Post Keynesian Workshop, Kansas, Missouri, June 29-July 3, 2002.

PATRAP, S. et al., "Debt Composition and Balance Sheet Effects of Exchange Rate Volatility in Mexico: A Firm Level Analysis", en Emerging Markets Review, vol. 4, núm. 4, diciembre 2003., pp. 450-471.

RAMÍREZ, E., "La búsqueda de motores de crecimiento bajo condiciones de liberalización económica”, en Contaduría y Administración, núm. 218, Facultad de Contaduría y Administración, Universidad Nacional Autónoma de México, enero-abril, 2006a.

de programa público de empleo (PPE)", en Problemas de desarrollo, Revista Latinoamericana de Economía, vol. 37, núm. 144, Instituto de Investigaciones Económicas, Universidad Nacional Autónoma de México, 2006b.

, "Por una política fiscal contracíclica", en Problemas de desarrollo, Revista Latinoamericana de Economía, vol. 37, núm. 147, Instituto de Investigaciones Económicas, Universidad Nacional Autónoma de México, 2006c.

RUIZ, A., El proceso de privatizaciones en Perú durante el periodo 1991-2002, Instituto Latinoamericano y del caribe de Planificación Económica y Social (ILPES), Comisión Económica para América Latina y el Caribe (CEPAL), Serie Gestión Pública, no. 22, Chile, julio 2002.

SAWYER, M., “On Budget Deficits and Capital Expenditure”, Working Paper núm. 208, The Levy Economics Institute of Bard College, octubre 1997.

SHESHINSKI, E. y L. LÓPEZ-CALVA, "Privatization and Its Benefits: Theory and Evidence”, CAER II Discussion Paper No. 35, dciembre 1998.

VIDAL, G., "Deuda externa, crédito e inestabilidad económica", en http://www. redcelsofurtado.edu.mx, 2004, consultado el 30 de marzo de 2005.

WRAY, R., "Internacional Aspects of Currency Monetary Policy", Center for Full Employment and Price Stability, University of Missouri-Kansas City, Working Paper No. 31, marzo 2004. 